\title{
Non-surgical Repair of Iatrogenic Furcal Perforation with Mineral Trioxide Aggregate: A Case Report
}

\author{
Sheikh $M A H^{1}$, Chowdhury $\mathrm{GM}^{2}$, Rab $\mathrm{MA}^{3}$, Naser $M^{4}$
}

\begin{abstract}
Perforations are significant iatrogenic complications of endodontic treatment and could lead to endodontic failure. The prognosis is generally excellent if the problem is well-diagnosed and repair is well-performed with a material that can provide proper sealing ability and biocompatibility. In this case report, the patient presented with the complaint of continuous dull pain in his right mandibular first molar tooth. The tooth was attempted for endodontic treatment and perforation has occurred at that time. Radiographic examination revealed, destruction in the furcal area with a little radiolucency and periradicular lesion involving apical region of the roots. Considering the above conditions, endodontic treatment and nonsurgical repair of furcal perforation with mineral trioxide aggregate followed by permanent restoration was planned and performed successfully. Follow up after one month, the patient was symptomless and the affected area was found healthy. However, long term clinico- radiographic follow-up is essential.
\end{abstract}

Key-words: Furcal Perforation, Mineral Trioxide Aggregate and Repair.

\section{Introduction}

Perforations are pathologic or iatrogenic communication between the root canal system and the attachment apparatus ${ }^{1}$. It can occur at any stage while performing endodontic therapy that is during access cavity preparation or during instrumentation or due to pathological condition such as caries, root resorption etc. The result is a chronic inflammatory reaction of the periodontium (characterized by the formation of granulation tissue) that can lead to irreversible loss of attachment or loss of the tooth ${ }^{2}$. Such perforations are managed surgically or non-surgically, depending on the particular characteristics of the case ${ }^{3}$. Various materials have been used in managing perforations including Amalgam, Intermediate Restorative Material (IRM), Super EBA, Cavit, Glass lonomer and composites; recently Mineral Trioxide Aggregate (MTA) and biodentine are advocated ${ }^{4}$. The present case report describes nonsurgical repair of floor perforation on the right mandibular first molar using MTA.

MTA is a mineral powder composed of thin hydrophilic particles of tricalcium silicate, tricalcium aluminate, tricalcium oxide, silicate oxide, besides small amounts of other mineral oxides and bismuthoxide, which provides it radiopacity ${ }^{5,6}$. It has been regarded as an ideal material for perforation repair, retrograde filling, pulp capping and apexification. When used as a repair material for perforation, MTA has many favourable properties including a good sealing characteristic, biocompatibility, bacteriostatic or bactericidal, radiopacity and ability to set up in the presence of blood ${ }^{7,8,9}$.

\section{Case Report}

A 30 years old male patient reported to the Department of Conservative Dentistry and Endodontics with the complaint of continuous dull pain in his right mandibular first molar. The tooth was attempted for endodontic treatment and perforation had occurred at that time. On clinical examination, the tooth was sensitive to percussion and palpation. The mean probing pocket depth was within normal level $(2 \mathrm{~mm})$. Radiographic examination revealed, destruction in the furcal area with a little radiolucency and periradicular lesion involving apical region of the roots. The condition was diagnosed as symptomatic chronic apical periodontitis along with floor perforation. Considering

1. Maj Md Abdul Hannan Sheikh, BDS, MCPS, DCD, FCPS, Graded Specialist in Conservative Dentistry and Endodontics, CMH, Dhaka 2. Brig General Golam Mohiuddin Chowdhury, BDS, FCPS, Adviser Spl in Dentistry, CMH, Dhaka 3. Col Md Abdur Rab, BDS, FCPS, Classified Specialist in Oral and Maxillofacial Surgery, CMH, Dhaka 4. Lt Col Mohammad Naser, BDS, FCPS, Classified Specialist in Conservative Dentistry and Endodontics, CMH, Dhaka. 
the above conditions, endodontic treatment and nonsurgical repair of furcal perforation with mineral trioxide aggregate followed by permanent restoration was planned.

\section{Treatment Procedure}

The whole treatment procedure was explained to the patient and consent was taken. After isolation of the operative field with cotton roll, the temporary restorative material was removed from the tooth and the perforation area was clinically seen. Haemorrhage was controlled by copious irrigation with $0.9 \%$ saline solution. A cotton pellet was placed in the orifice of perforation. Working length measuring radiograph was taken. The root canal was cleaned and shaped according to standardized technique. Before the use of each instrument, an irrigation of canal was performed using 2\% Chlorhexidine $(\mathrm{CHX})$ and immediately rinsed with normal saline. Then calcium hydroxide dressing was given for one week. On the next visit, root canals were irrigated with large volume of normal saline. Then the canals were dried and obturation was done. Then the perforation was sealed with white MTA (Angelus, Brazil) mixed with distilled water, as suggested and supplied by manufacturer. One sachet of MTA was mixed with one drop of distilled water for thirty seconds on a sterile glass slab by a stainless steel spatula. It was placed on the perforation site with a sterilized amalgam gun and was condensed with dam cotton. A small wet cotton pellet was placed in contact with MTA. Then the rest of the chamber was closed with glass ionomer. After 24 hours, removal of temporary cement was done to check if MTA was set. Then, the tooth was restored with direct restorative material named miracle mix. Bite was checked and post operative radiograph was taken. Follow up after one month the patient was symptomless and the tooth was healthy.

\section{Discussion}

The prognosis of perforations depends on the location, size and time of contamination of the lesion. The location of furcal perforations at the level of the epithelial attachment and crestal bone suggested a guarded prognosis ${ }^{10}$. Secondly, the size of a perforation represents another important factor in determining the success of the repair procedure; some authors suggested the use of internal matrix to avoid the extrusion of the sealing material and consequent periradicular tissue inflammation ${ }^{11}$. In this case, furcal perforation was small, with a low risk of filling material extrusion. Finally, interval between perforation and repair is one of the critical factors for success $^{12,13}$. Immediate sealing of perforations enhances the repair process by reducing the possibility of bacterial contamination of the defect ${ }^{14}$. Holland et al showed that the lateral root perforations sealed with MTA after contamination presented worse repair than the non-contaminated, immediately sealed perforations $^{15}$.

In the present case, although the time between perforation and repair was two weeks, MTA treatment was successful. In another study, the time elapsed from the creation of the perforation to repair of the defect did not exceed 6 months and the use of MTA to seal furcal perforation was associated with a good short term clinical outcome ${ }^{16}$. In this case, the perforation defect was managed non-surgically as it was non-invasive, less technique sensitive, cost effective and prognosis is usually better than that of surgical procedure. Other options for perforation repair include premolarization and hemisection. These are indicated where periodontal involvement of one root is severe, loss of bone is extensive in the furcation area and when extensive bone loss has occurred around one root of molar.

Other than an accurate diagnosis and immediate treatment planning, a suitable material is also a key element in successful sealing of perforation ${ }^{17}$. An ideal material should adhere to the root canal wall while maintaining appropriate sealing and should be biocompatible or bioactive. In addition material should be dimensionally stable, insoluble in tissue fluid, non resorbable and also radio- opaque ${ }^{18}$. Many materials can be used to repair perforation including amalgam, composites and zinc oxide eugenol cements. However, these materials require a dry field and they don't promote new tissue formation. For these reasons, these materials were not used in the present case. 
In this case, MTA was used to repair furcal perforation as it has fulfilled the criteria of an ideal material such as biocompatibility and superior seal when compared to amalgam, IRM and Super EBA. MTA is the only material that is not affected by moisture or blood contamination. It has high $\mathrm{pH}$ (12.5) which promotes growth of cementum and regeneration of periodontal ligament ${ }^{19,20}$. MTA is primarily composed of calcium and phosphate ions, which are also the main constituents of the dental hard tissues ${ }^{21}$. This resemblance in chemical composition to the tooth structure, the ability of MTA to release $\mathrm{Ca}^{+3}$ ions and its capacity to form hydroxyapatite are stated to be the factors responsible for its sealing ability, biocompatibility and dentinogenic activity ${ }^{22}$. Microscopic examination of periodontal tissues after perforation in the furcal area and subsequent sealing with MTA demonstrated repair of the periodontium, and new cementum formation over the material ${ }^{23}$.

The control of inflammatory process in the defect area during the management of perforation represents one of the main goals of the treatment, in addition to promoting the health of the surrounding tissue $^{24}$. To achieve a better tissue response, in this case the perforation site was disinfected with $2 \%$ Chlorhexidine. Sodium Hypochlorite $(\mathrm{NaOCl})$ was avoided because it is known that it can be extremely aggressive and cause damage to the surrounding tissue. Chlorhexidine has been recommended by several authors as an auxiliary chemical substance ${ }^{25}$, as, in addition to being relatively non-toxic when compared to $\mathrm{NaOCl}$, it has strong antimicrobial power and prolonged time of action. This property may offer clinical advantage of using Chlorhexidine in furcal perforations.

The evaluation criteria for determining success following treatment of a perforated tooth include absence of symptoms, such as spontaneous pain or pain on palpation or percussion, absence of excessive mobility, absence of communication between the perforation and the gingival crevice, absence of fistula, absence of radiographic signs of demineralization of the bone adjacent to the perforation and the treated tooth must be functional ${ }^{26,27}$.

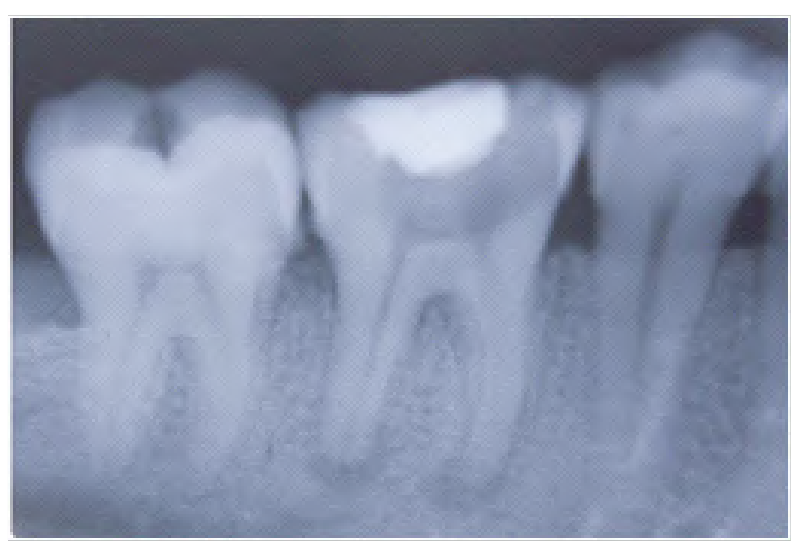

Fig-1: Initial X-Ray

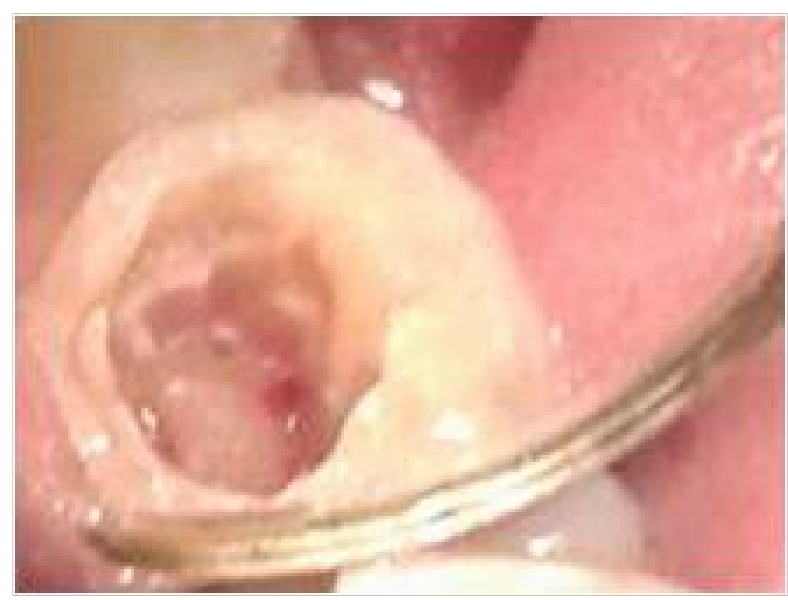

Fig-2: Site of Perforation

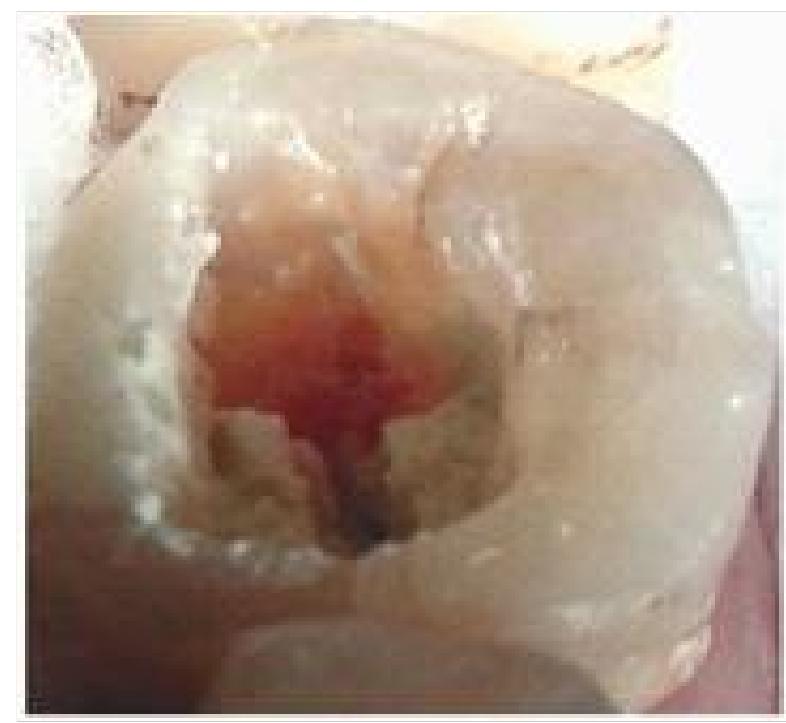

Fig-3: Repair of Perforation with MTA 


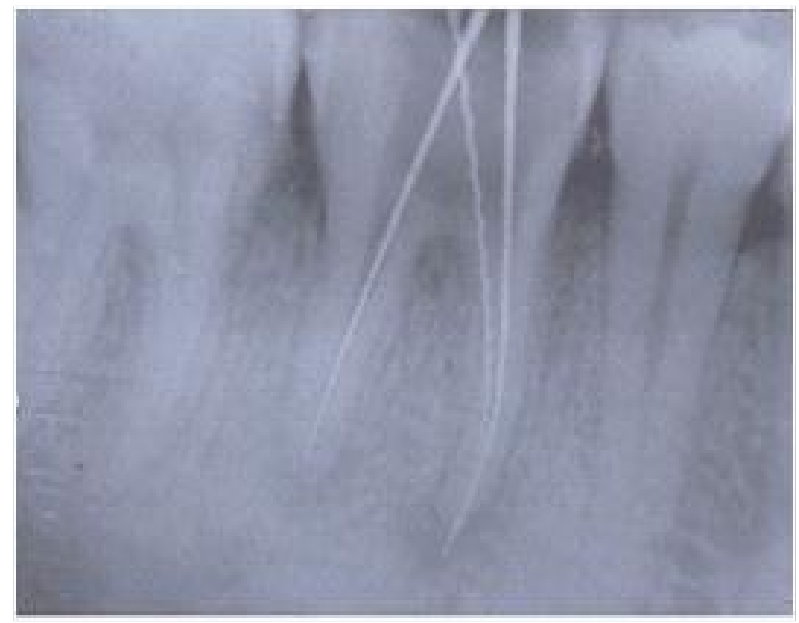

Fig-4: Working length determination

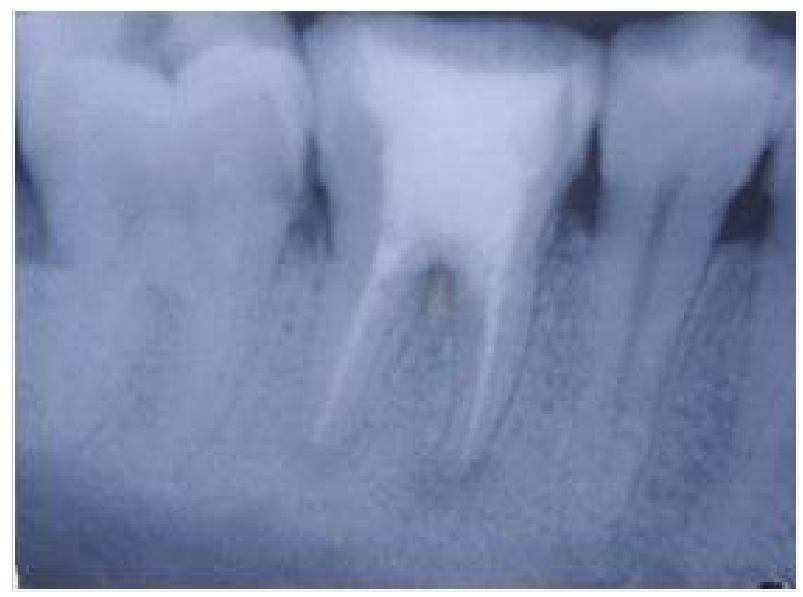

Fig-5: Final X-Ray after obturation

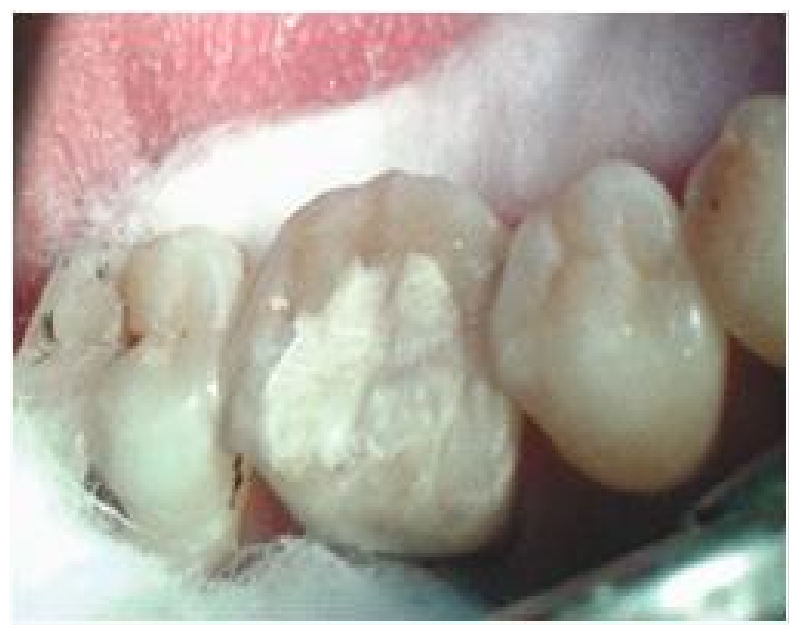

Fig-6: After placement of restoration

\section{Conclusion}

The prognosis of perforated teeth is better now-a-days than it was in the past, and this is due to the improved vision as well as the use of biocompatible materials such as MTA. Based on the outcome of present case, it can be concluded that furcal perforation can be repaired non-surgically by using MTA. To determine the long term prognosis patient's symptoms, radiographic changes and periodontal status should be monitored.

\section{References}

1. Castellucci A. The Use of Mineral Trioxide Aggregate to Repair latrogenic Perforations. Dentistry Today. 2008 September; 48-51.

2. Al-Daafas A, Al-Nazhan S. Histological evaluation of contaminated furcal perforation 2007; 103(3).

3. Roda Rs. Root perforation repair; Surgical and non-surgical management. Pract proced Aesthet Dent 2001; 13(6):467-7.

4. Fuss Z, Trope M. Root perforations: Classification and treatment choices based on prognostic factors. Endod Dent Trumatol 1996; 12(6):255-64.

5. Lee SJ, Monsef M, Torbinejad M. Sealing ability of a mineral trioxide aggregate for repair of lateral root perforations. J Endod 1993; 19:541-4.

6. Main C, Mirzayan N, Shabahang S et al. Repair of root perforations using mineral trioxide aggregate: $\mathrm{A}$ long-term study. J Endod 2004; 30:80-3.

7. Menezes R, Xavier da Silva Neto U, Carneiro E et al. MTA repair of a supracrestal perforation: A case report. Journal of Endodontics 2005; 31(3):212-4.

8. Lee SJ, Monsef M, Torabinejad M. Sealing ability of a mineral trioxide aggregate for repair of lateral root perforations. Journal of Endodontics 1993; 19(11):541-4.

9. Roberts HW, Toth JM, Berzins DW, et al. Mineral trioxide aggregate material use in endodontic treatment: A review of the literature. Dental Materials. 2008; 24(2):149-64. 
10. Tsesis I, Rosen E, Schwartz-Arad D et al. Retrospective evaluation of surgical endodontic treatment: traditional versus modern technique. J Endod 2006; 32:412-6.

11. Rafter M, Baker M, Alves $M$ et al. Evaluation of healing with use of an internal matrix to repair furcation perforations. Int Endod J 2002: 35:775-83.

12. Wu M, Kontakiotis EG, Wesselink PR. Long-term seal provided by some root-end filling materials. J Endod 1998; 24:557-60.

13. Alhadainy HA. Root perforations. Oral Surg Oral Med Oral Pathol Oral Radiol Endod 1994; 78:368-74.

14. Main C, Mirzayan N, Shabahang S et al. Repair of root perforations using mineral trioxide aggregate: a long-term study. J Endod 2004; 30:80-3.

15. Holland R, Bisco Ferreira L, de Souza V, et al. Jr Reaction of the lateral periodontium of dogs' teeth to contaminated and noncontaminated perforations filled with mineral trioxide aggregate. J Endod 2007; 33:1192-7.

16. Pace R, Giuliani V, Pagavino G. Mineral trioxide aggregate as repair material for furcal perforation: case series. J Endod 2008; 34:1130-3.

17. Ingle JI, Simon JH, Machtou P et al. Outcome of endodontic treatment and retreatment. In: Ingle JI, Bakland LK, editors. Endodontics. 5th ed. London: BC Decker Inc 2002; 753-5.

18. Tavane PN. Endodontic harvesting of furcal perforation with Mineral Trioxide Aggregate: a case report. J Int Oral Health 2010.
19. Parirokh $\mathrm{M}$, Torabinejad $\mathrm{M}$. Mineral trioxide aggregate: A comprehensive literature review-part 1: Chemical, physical and antibacterial properties. J Endod 2010; 36:16-27.

20. Roberts HW, Toth JM, Berzins DW et al. Mineral trioxide aggregate material use in endodontic treatment: A review of literature. Dent Mater 2008; 24:149-64.

21. Camilleri J, Montesin FE, Brady $\mathrm{K}$ et al.The constituent of mineral trioxide aggregate. Dent Mater 2005; 21:297-303.

22. Sarkar NK, Caicedo R, Ritwik P, et al. Physicochemical basis of the biologic properties of mineral trioxide aggregate. J Endod 2005; 31:97-100.

23. Pitt Ford TR, Torabinejad M, McKendry DJ et al.SP. Use of mineral trioxide aggregate for repair of furcal perforations. Oral Surg Oral Med Oral Pathol Oral Radiol Endod 1995; 79:756-63.

24. Vanderweele RA, Schwartz SA, Beeson TJ. Effect of blood contamination on retention characteristics of MTA when mixed with different liquids. J Endod 2006; 32(5): 421-4.

25. Roy CO, Jeansonne BG, Gerrets TF. Effect of an acid environment on leakage of root-end filling materials. J Endod 2001 Jan; 27(1):7-8

26. Bargholz C. Perforation repair with mineral trioxide aggregate: a modi- fied matrix concept. Int Endod J 2005; 38(1):59-69.

27. Schwartz RS, Mauger M, Clement DJ et al. Mineral trioxide aggregate: a new material for endodontics. J Am Dent Assoc 1999 Jul; 130(7):967-75. 